\title{
Mass balance-based regression modeling of PAHs accumulation in urban soils, role of urban development
}

\author{
Chi Peng a, Meie Wang a , Weiping Chen ${ }^{\mathrm{a},{ }^{*}, \text { Andrew C. Chang }}{ }^{\mathrm{b}}$ \\ a State Key Laboratory of Urban and Regional Ecology, Research Center for Eco-Environmental Sciences, Chinese Academy of Sciences, Beijing 100085, PR \\ China \\ ${ }^{\mathrm{b}}$ Department of Environmental Sciences, University of California, Riverside, CA 92521, United States
}

\section{A R T I C L E I N F O}

\section{Article history:}

Received 15 September 2014

Received in revised form 19 November 2014

Accepted 22 November 2014

Available online 6 December 2014

\section{Keywords:}

Mass balance model

Urbanization

Residential areas

Energy utilization

Industrial transformation

Polycyclic aromatic hydrocarbons

Beijing

\begin{abstract}
A B S T R A C T
We investigated the polycyclic aromatic hydrocarbons (PAHs) contents in 68 soils samples collected at housing developments that represent different length of development periods across Beijing. Based on the data, we derived a mass balanced mathematical model to simulate the dynamics of PAH accumulations in urban soils as affected by the urban developments. The key parameters were estimated by fitting the modified mass balance model to the data of PAH concentrations vs. building age of the sampling green area. The total PAH concentrations would increase from the baseline of $267 \mathrm{ng} \mathrm{g}^{-1}$ to $3631 \mathrm{ng} \mathrm{g}^{-1}$ during the period of 1978-2048. It showed that the dynamic changes in the rates of accumulations of light and heavy PAH species were related to the shifting of sources of fuels, combustion efficiencies, and amounts of energy consumed during the course of development.
\end{abstract}

๑) 2014 Elsevier Ltd. All rights reserved.

\section{Introduction}

Polycyclic aromatic hydrocarbons (PAHs) are ubiquitous in urban environments. The United States Environmental Protection Agency (USEPA) listed 16 PAHs as priority pollutants because of their frequent occurrences, environmental toxicities, and potential human exposures in urban settings (Hao et al., 2007). Natural processes including volcanic eruptions, forest fires and biosynthesis have emitted PAHs (Gocht et al., 2007; Ravindra et al., 2008). The PAHs found in atmospheric and terrestrial environment however came primarily from anthropogenic emission sources due to incompletion combustions of fuels in industrial processing, power generations, waste incineration, vehicle emissions, cooking and space heating, and wood and biomass burnings (Heywood et al., 2006; Liu et al., 2006). Once released, the airborne PAHs would be suspended for a long time and subject to long distance transportation (Sun et al., 2009) and eventually 90\% of the PAHs would be deposited on soil surfaces in and surrounding population centers (Gocht et al., 2007; He et al., 2009). The strong adsorption by soil

\footnotetext{
* Corresponding author.

E-mail address: wpchen@rcees.ac.cn (W. Chen).
}

organic matter would inhibit their degradation, leaching, and volatilization losses (Yu et al., 2006) resulting in accumulation of PAHs in top soils (Gocht et al., 2007).

Geographically urban centers are hot spots of PAH emissions (Wong et al., 2004). Dense population, teeming commercial and industrial activities in urban metropolises create heavy traffic volumes, consume huge amount of energy, and produce vast wastes, all PAH generators (Peng et al., 2011). Urban soils being in close proximity of emission sources are expected to accumulate a great deal of fugitive PAHs (Nam et al., 2008) and PAH concentration of urban soils appear to change in proportion with extent of cities are being urbanized and industrialized (Augusto et al., 2009; Jensen et al., 2007; Wei et al., 2014). If the temporal trends in urban development parallel the PAH accumulation pattern of soils (Guo et al., 2006; Harrison et al., 1996; Yan et al., 2009), the interrelationships are imperative for better planning of urban land uses, traffic networks, and residential communities. The current database consisted of primarily one time survey of PAH accumulation in urban soils with the soil samples collected at uncoordinated times and unrelated locations. How may the dynamic processes of $\mathrm{PAH}$ accumulation in urban soils be tracked over the time of development? 
Mathematical models might be employed to envision fates, transport, interactions, spatial distribution and potential risk of pollutants persisting in the environment (Kubosova et al., 2009; Poggio et al., 2008; Tao et al., 2003; Wania and McLachlan, 2001). Environmental models designed for some specific purposes would be less effective in other research fields, such as fugacity models were expert in modeling pollutants partitioning between media (Mackay, 2001), GIS-based watershed model were suitable for modeling pollutants transport and distribution with water flows (Galván et al., 2009), and mechanism models were commonly employed for predicting a specific environmental process of pollutants in the environment, e.g. leaching or plant uptake (Chen et al., 2013; Chiou et al., 2001). The mass balance model was able to track long-term accumulation of pollutants in soils with minimal mathematical parameters. Chen et al. (2007) demonstrated the long-term accumulation of fertilizer-borne As and Cd in cropland soils using a mass balance model that included key reactive processes governing the input and out fluxes. However, validating efficacy of the model would be problematic as required data were often unavailable.

The accumulation of PAHs in soils are affected simultaneously by the duration soils have been exposed to pollutant fallouts and spatial factors including sources distribution, land use categories, vegetation structures, population density, and soil properties (Jensen et al., 2007; Nam et al., 2008; Peng et al., 2012; Staci L. and Simonich, 1994; Yu et al., 2006). The residential neighborhoods are sheltered from intense emission sources and allowed discharged PAHs to intermingle before falling out (Peng et al., 2013). The open and green spaces inside these housing developments are similar in ecological settings and in soil and vegetation management strategies reducing interferences of spatial factors over the time. Therefore, community housing developments would be idea to examine the dynamics of soil PAH accumulation over urban development.

In this research, we chose Beijing, a city experiencing rapid urbanization and deep transformation in terms of demographics, infrastructural renewals, and industrialization in last 30 years, as an example to study temporal changes of soil PAHs accumulation during the course of urban development. The main objectives are to: 1) Use soil samples that represented varying lengths of development period, from 1 to 30 years, to deduce the dynamics of $\mathrm{PAH}$ accumulation over time in Beijing. 2) Develop a mathematical model to simulate the dynamic changes of soil PAH concentrations over time. 3) Evaluate impacts of urban development on $\mathrm{PAH}$ accumulation of urban soils in Beijing.

\section{Material and analysis}

\subsection{Study area}

Beijing has doubled the urban area, undergone complete overhaul of infrastructures, and changed the energy consumption patterns in last 30 years. From 1978 to 2008, its population grew from 8.7 to 17.0 million people and the gross domestic product (GDP) increased from 10.9 to 1111.5 billion Yuan RMB (BSB, 2009). It evolved from a traditional heavy industry based smock stack city into a politico-commercial-cultural center. All aspects of the environment have vastly improved as the traditional industries were replaced by the tertiary industries. In 1978, the gross industrial production was $64.5 \%$ of the GDP. In $2008,19.0 \%$ of the GDP associated with the industrial sector. The urban green space had risen from $22.3 \%$ of the old city in 1978 to $44.4 \%$ of the expanded new metropolis in 2008 (BSB, 2009). With the redevelopments and new developments, the PAH emission patterns continued to evolve.

\subsection{Sampling}

We collected 68 soils $(0-10 \mathrm{~cm}$ depth) at the green areas of randomly selected housing development projects inside the 5th ring road of Beijing (roughly $650 \mathrm{~km}^{2}$ ). Detailed sampling strategy could be found in reference (Peng et al., 2013). The previous study suggested that $59 \%$ of the PAHs in those soils were resulted from a citywide uniform baseline deposition (Peng et al., 2013). The establishment time was known for each sampling sites. They represented soils of Beijing that had exposed to different durations of urban development $(x)$. Each specimen was the mixture of 5 soil cores obtained within boundaries of the community green space. The samples were stored in paper bags, transported to the laboratory, dried at room temperature, ground to pass a sieve of $2 \mathrm{~mm}$ openings, and stored in amber color glass containers in freezer at $-25{ }^{\circ} \mathrm{C}$ waiting for the chemical analysis.

\subsection{Chemical analysis}

The method employed to determine PAH contents of soils was detailed in Peng et al. (2011). Briefly, $5 \mathrm{~g}$ aliquot of soil was mixed with $5 \mathrm{~g}$ sodium sulfate, extracted in an automated Soxhlet extraction apparatus with $120 \mathrm{ml}$ equal volume mixture of acetone - dichloromethane for $2 \mathrm{~h}$. The extract was concentrated and then purified by pass through a silica gel solid-phase extraction column (Supco, Inc., USA). The collected drainage were analyzed by an Agilent 6890 gas chromatography equipped with a 5975C mass selective detector (GC-MSD, Agilent, Inc., USA) through external standard method. Sixteen USEPA priority PAHs were determined namely naphthalene (NAP), acenaphthylene (ACPY), acenaphthene $(\mathrm{ACP})$, fluorene (FL), phenanthrene (PHE), anthracene (ANT), fluoranthene (FLT), pyrene (PYR), chrysene (CHR), benzo(a)anthracene $(\mathrm{BaA})$, benzo(k)fluoranthene $(\mathrm{BkF})$, benzo(b)fluorantene $(\mathrm{BbF})$, benzo(a)pyrene (BaP), dibenzo(a, h)anthracene(DBA), indeno(1, 2, 3- cd)pyrene (IND), and benzo(g, h, i)perylene (BghiP).

\subsection{Data preparation and statistical analysis}

SigmaPlot (vision 12.0) was used for regression analysis and parameter estimation. In urban areas, some unforeseeable causes would lead to unusual high/low concentrations of PAH in the soils. To reduce the impacts of data variance on the regression estimates, we log-transformed the data to obtain an approximation of normal distribution (passed Kolmogorov-Smirnov test). Moreover, in the regression practices, the data points with large studentized residuals (outside the $95 \%$ confidence) were marked as outlying data and were eliminated from the raw datasets (e.g. four data points for PHE, and five data points for BaP). Other statistical analyses (e.g. Pearson correlation analysis) were carried out by using SPSS (version 18.0).

\section{Model development}

For PAHs accumulating in soils, the annual change of PAH concentrations may be described by a one-dimensional mass balance equation that:

$\frac{d M}{d t}=I-L$

where $M$ is total PAH concentration of soil $\left(\mu \mathrm{g} \mathrm{kg}^{-1}\right), I$ is annual PAH input flux ( $\mu \mathrm{g} \mathrm{kg}^{-1} \mathrm{yr}^{-1}$ ), $L$ is annual PAH outflux of the soil $\left(\mu \mathrm{g} \mathrm{kg}{ }^{-1} \mathrm{yr}^{-1}\right)$. Beijing has experienced fast urban expansion in recent decades. The population, coal consumption, vehicle number and GDP of Beijing showed approximate exponential increases 
during the period of 1978-2008 (BSB, 2009). The PAH accumulation in the surface soils has been considerable. We assume that annual changes of PAH input with respect to time (i.e. input flux) follows a first order reaction and is proportional to the input, $I$ :

$$
\frac{d I}{d t}=k_{i} * I
$$

where $k_{i}$ is the input change rate constant $\left(\mathrm{yr}^{-1}\right)$. Pathways for output of soil PAHs include leaching, degradation, volatilization, and uptake by plants. We assume that total loss is a constant fraction of the PAH concentration of soil (Mackay, 2001):

$$
L=k_{l} * M
$$

where $k_{l}$ is the soil PAH loss constant $\left(\mathrm{yr}^{-1}\right)$. Combing the Equation (1) through (3), the changes of total PAH concentration with respect to time is:

$$
M(t)=\int_{t_{0}}^{t}\left(I_{0} e^{k_{i} t}-k_{l} * M(t)\right)
$$

or

$M(t)=\frac{I_{0}}{k_{l}+k_{i}} e^{k_{i} t}+\left(M(0)-\frac{I_{0}}{k_{l}+k_{i}}\right) e^{-k_{l} t}$

where $t_{0}$ represents the initial time when it begins to urbanize, $I_{0}$ is the baseline input of PAHs at $t_{0}\left(\mu \mathrm{gg}^{-1} \mathrm{yr}^{-1}\right), M(0)$ is background concentration of PAHs in Beijing $\left(\mu \mathrm{g} \mathrm{kg}^{-1}\right)$, and $t$ is the number of years PAHs have been accumulating in a given soil. A set of data, $M(t)$ vs. $t$, is needed to define the equation parameters, $k_{l}$ and $k_{i}$, and initial values, $I_{0}$ and $M(0)$.

The modernization and urban renewal of Beijing began in 1978 and the developments expanded stepwise over time across the entire city. For the study, it would not be possible to go back in time and obtain retroactively soil samples from 1978 to the present. Instead, we were only able to collect soil samples at locations that represented different length of time (years) in housing development in 2008. While PAH accumulations in all soil samples followed the dynamics described in Equation (5), each sample nevertheless was represented by a different set of $I_{0}$ and had different initial time, $t_{0}$. As soil samples were collected at 2008, there has been a 30 year span since the advent of urbanization in Beijing. A location began urbanizing $t$ years after 1978 would have $30-t$ years of development, namely, the soils received $t$ years of the background inputs of PAH but not the added PAH inputs due to the urbanization. The time this location had been urbanized is $x$ (year) then:

$x=30-t$

In this manner, Equation (5) would have a different initial input, $I_{x}$, and the same equation parameters $k_{l}$ and $k_{i}$ and initial soil PAH, $M(0)$. Mathematically, the initial inputs of the soil samples might be determined as:

$I_{x}=I_{0} e^{k_{i}(30-x)}$

Substituting $I_{X}$ for $I_{0}$ in Equation (5) and integrating.

$M(x)=\frac{I_{0} e^{30 k_{i}}}{k_{l}+k_{i}}+M(0) e^{-k_{l} x}-\frac{I_{0} e^{30 k_{i}}}{k_{l}+k_{i}} e^{-\left(k_{i}+k_{l}\right) x}$

The mathematical form of Equation (5) applicable to data of $M(t)$ vs. $t$ was transformed into a new mathematical form of Equation (8) applicable to data of $M(x)$ vs. $x$.

Fitting soil PAH concentrations vs. time (i.e. years the location had been urbanized at the time of soil sampling) to Equation (8), the background concentrations of PAH in Beijing $M(0)$, the 1978 baseline PAHs input $I_{0}$ and parameters $k_{i}$ and $k_{l}$ might be obtained. When the model parameters and initial values obtained in this manner were adopted in Equation (5), the temporal dynamics of PAHs accumulations in Beijing soils from 1978 to 2008, were delineated.

The distribution patterns of PAH congeners in urban soils affected by diffuse sources were rather stable (Peng et al., 2012), and therefore compounds representing a range of physicochemical properties of PAHs could be selected for parameter estimation (further details can be found in Section 4.1). Due to the high degrees of freedom in Equation (8), priori information was prerequisite for a robust result. The previously reported decay rates (half-lives) of PHE and BaP in soils at low concentration condition were used as the loss constants $k_{l}$ in Equation (8) (Aronson et al., 1998; Wild et al., 1991). After that, the results of parameter estimation became robust and rarely changed when up to $30 \%$ of data points were randomly deleted.

\section{Results and discussion}

\subsection{Soil PAHs accumulation and classification}

The greeneries in the housing projects have similar ecological settings and were managed more or less in the same fashion. To facilitate vegetation transplanting, the original soils of these green spaces were covered with fertile and fresh soils, which were normally transported from outskirts of the city during the processes of land use change. In most cases, the new soil layer had a higher horizontal plane than the surrounding impervious grounds. As the soils were disturbed and moved at the time of development, it would be reasonable to assume that in each housing project the PAH accumulation began at same baseline level. The housing projects with various building age suggesting that the green soils were exposed to the urban atmospheric deposition for different years. The total PAH concentrations of Beijing residential soils ranged from 180 to $4092 \mathrm{ng} \mathrm{g}^{-1}$ with an arithmetic mean of $865 \mathrm{ng} \mathrm{g}^{-1}$. The average concentrations were comparable with outcomes of previous PAH investigations in Beijing (mean $=694 \mathrm{ng} \mathrm{g}^{-1}, n=12$ ) and Shanghai (mean $=1260 \mathrm{ng} \mathrm{g}^{-1}, n=12$ ) (Jiang et al., 2009; Liu et al., 2010). The distribution of data was skewed towards the lower PAH concentrations showed lognormal distributions. The wide range distribution of PAH concentrations reflected the progression in urban development over time. The high concentrations were found at locations representing longest periods of exposures (Fig. 3).

The $16 \mathrm{PAH}$ species have different physicochemical properties and once released will experience different extent of environmental fate and transport (Ma et al., 2011; Ravindra et al., 2008; Tao et al., 2003; Wang et al., 2011). As molecular weight, octanol-water partitioning coefficient $\left(K_{\mathrm{ow}}\right)$ and Henry's Law constant of PAHs characterize their environmental fate and transport (Table S1), it is commonly group the 16 PAHs into two classes according to their molecular weight and environmental behavior, namely low molecular weight PAHs (LMW PAHs including NAP, ACPY, ACP, FL, PHE, and ANT) and high molecular weight PAHs (HMW PAHs including FLT, PYR, BaA, CHR, BbF, BkF, BaP, IND, DBA, and BghiP). LMW PAHs would be environmentally more reactive. It spreads farther from the emission sources and disappears from the urban ecosystems more rapidly than HMW PAHs. On the other hand, HMW PAHs are more environmental resistant to degradation and prone to adsorb 


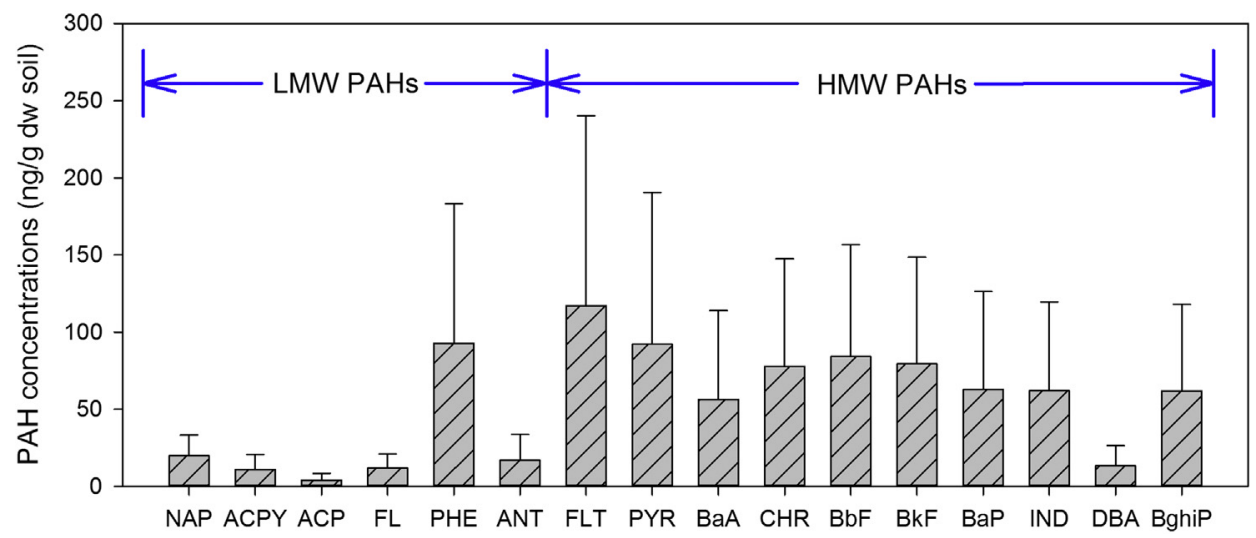

Fig. 1. Concentrations of the $16 \mathrm{PAH}$ congeners in the residential soils of Beijing.
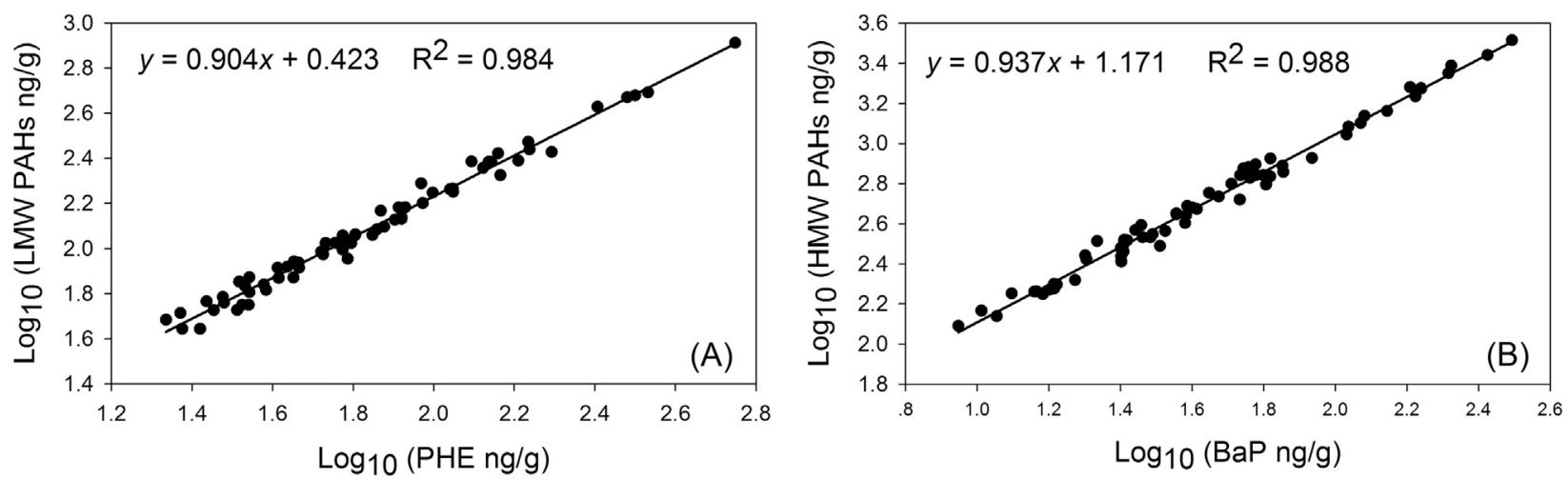

Fig. 2. Linear regressions of PHE vs. LMW PAHs and BaP vs. HMW PAHs in the residential soils of Beijing.
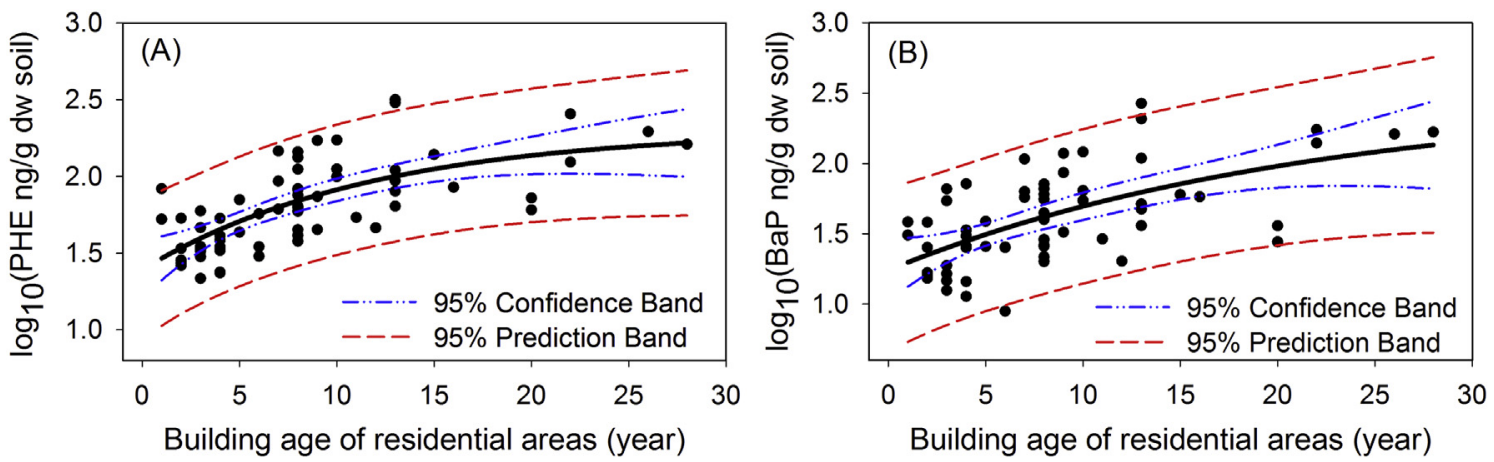

Fig. 3. Measured PAH concentrations and $M(x)$ vs. $x$ according to Equation (8).

on soil organic matter. They accumulate in soils for a longer time than LMW PAHs.

The soil samples were collected to represent different durations of PAH exposures. While 16 PAHs were all found in the soils, species belonging to HMW PAHs were prominent (Fig. 1), especially at locations of earlier development. The $16 \mathrm{PAH}$ congeners were strongly correlated with each other as well as the total PAH concentrations (Table 2). To simplify the modeling processes, we tend to simulate one or two PAH congeners that could represent the general deposition trend of the whole PAH species. LMW PAHs and HMW PAHs were considered separately due to their difference in environmental behavior. Among the 16 PAH species, PHE and BaP had the highest correlation with LMW PAHs and HMW PAHs respectively (Table 2). Liner regressions showed the determination coefficients $\left(R^{2}\right)$ were 0.984 for PHE vs. LMW PAHs and 0.988 for BaP vs. HMW PAHs suggesting that modeling the accumulation of

Table 1

Nonlinear regression fitting field data to Equation (8).

\begin{tabular}{lllllrl}
\hline Compound & $R^{2}$ & $p$ & $M(0)$ & $k_{l}\left(\mathrm{yr}^{-1}\right)$ & $k_{i}\left(\mathrm{yr}^{-1}\right)$ & $I_{0}^{\mathrm{a}}$ \\
\hline PHE & 0.47 & $<0.0001$ & $1.39\left(24.7 \mathrm{ngg}^{-1}\right)^{\mathrm{a}}$ & $0.0693^{\mathrm{b}}$ & 0.0062 & 0.1439 \\
$\mathrm{BaP}$ & 0.37 & $<0.0001$ & $1.25\left(17.7 \mathrm{ngg}^{-1}\right)$ & $0.0475^{\mathrm{c}}$ & -0.0006 & 0.1178 \\
\hline
\end{tabular}

a Values in brackets indicate antilog of $M(0)$.

b The degradation rate of PHE were from Wild et al. (1991).

c The degradation rate of BaP were from Aronson et al. (1998). 
Table 2

Correlations between PAH congeners and total PAH concentrations.

\begin{tabular}{llll}
\hline & LMW-PAHs $^{\mathrm{a}}$ & HMW-PAHs $^{\mathrm{b}}$ & $\sum \mathrm{PAHs}$ \\
\hline NAP & $0.373^{* *}$ & $0.157^{* *}$ & 0.195 \\
ACPY & $0.780^{* *}$ & $0.762^{* *}$ & $0.773^{* *}$ \\
ACP & $0.895^{* *}$ & $0.868^{* *}$ & $0.882^{* *}$ \\
FL & $0.909^{* *}$ & $0.821^{* *}$ & $0.844^{* *}$ \\
PHE & $0.979^{* *}$ & $0.937^{* *}$ & $0.954^{* *}$ \\
ANT & $0.933^{* *}$ & $0.954^{* *}$ & $0.961^{* *}$ \\
FLT & $0.931^{* *}$ & $0.988^{* *}$ & $0.989^{* *}$ \\
PYR & $0.917^{* *}$ & $0.987^{* *}$ & $0.985^{* *}$ \\
BaA & $0.905^{* *}$ & $0.994^{* *}$ & $0.990^{* *}$ \\
CHR & $0.923^{* *}$ & $0.994^{* *}$ & $0.992^{* *}$ \\
BbF & $0.919^{* *}$ & $0.990^{* *}$ & $0.989^{* *}$ \\
BkF & $0.918^{* *}$ & $0.993^{* *}$ & $0.991^{* *}$ \\
BaP & $0.916^{* *}$ & $0.996^{* *}$ & $0.993^{* *}$ \\
IND & $0.903^{* *}$ & $0.983^{* *}$ & $0.980^{* *}$ \\
DBA & $0.891^{* *}$ & $0.985^{* *}$ & $0.980^{* *}$ \\
BghiP & $0.895^{* *}$ & $0.985^{* *}$ & $0.980^{* *}$ \\
\hline
\end{tabular}

${ }^{* *}$ Correlation is significant at the 0.01 level (2-tailed).

a LMW PAHs denotes low-molecular-weight PAHs containing 2-3 rings.

b HMW PAHs denotes high-molecular-weight PAHs containing 4-6 rings.

PHE and BaP were enough to predict the dynamics of total PAH concentrations in the soils (Fig. 2).

\subsection{Regression estimates of PAHs accumulation}

The model parameters $M(0), k_{i}$, and $I_{0}$ were essential for prediction of PAH accumulation in urban soils. We fitted the data to the modified mathematical form, Equation (8), from which $k_{i}, M(0)$, and $I_{0}$ were estimated (Fig. 3). The $k_{l}$ was preset to 0.0693 for PHE and 0.0475 for BaP based on references (Table 1). The dynamic accumulations of PHE and BaP over development time were simulated to represent the accumulation processes of semi-volatile and resistant PAH species. The regressions of $M(x)$ vs. $x$ according to Equation (8) were significant at $p<0.001$ and $R^{2}$ were 0.47 for PHE and 0.37 for BaP (Table 1 ). The data uncertainty had several causes, including (1) the simplicity of model hypothesis on the inputs and outputs of soil PAHs, (2) The strategy of trading space for time since we were unable to obtain a long-term in situ monitoring data, (3) and the high complexity and heterogeneity of the urban area. Yet, the regression estimates were robust and should be the statistically

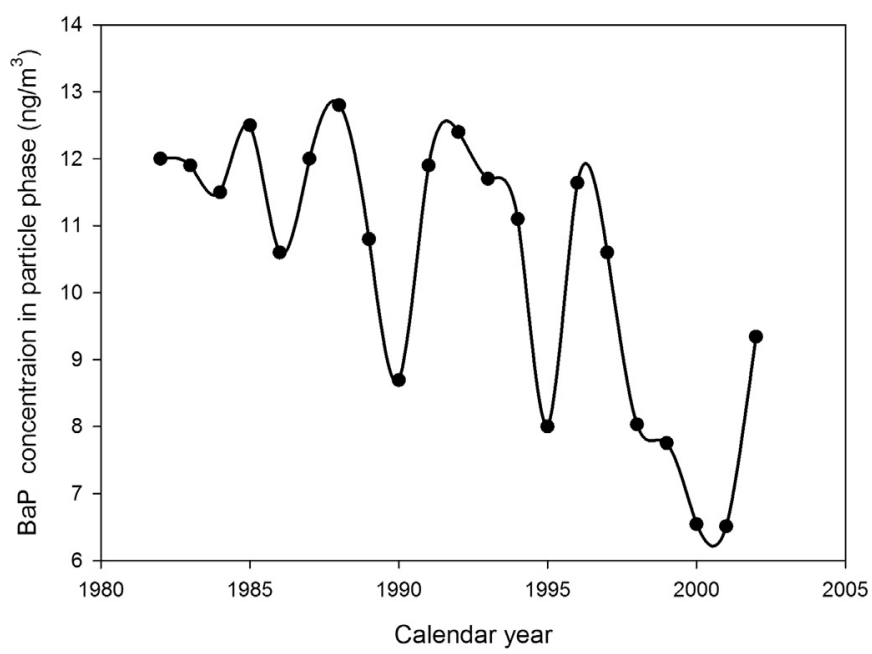

Fig. 4. Atmospheric BaP concentrations in the urban Beijing, 1980 to 2002 (BMEPB, 2003). optimal solutions for explore the general patterns of PAHs accumulation accompanied by urban development.

Parameter $k_{i}$ denoted the PAH input change rate over the 1978 to 2008 development period in Beijing. The $k_{i}$ for PHE, and BaP were $6.2 \times 10^{-3} \mathrm{yr}^{-1}$ and $-6.0 \times 10^{-4} \mathrm{yr}^{-1}$, respectively. The fitted $k_{i}$ of $\mathrm{BaP}$ were slightly below zero suggested a changeless or decrease trend of BaP deposition in the period. This fact was supported by BMEPB (2003) results of the airborne BaP concentrations in the urban area of Beijing from 1980 to 2002 (see Fig. 4). In addition, Ma et al. (2011) reported that the total atmospheric concentration of $\mathrm{BaP}$ in the gas and particle phases of urban Beijing were $9.3 \mathrm{ng} \mathrm{m}^{-3}$ in 2008, which was similar to BMEPB results at 2002. On the contrary, the fitted $k_{i}$ of PHE were slightly above zero suggesting that recent emissions played a more significant role for the LMW PAHs. Unfortunately, PHE was not monitored by the BMEPB air quality monitoring network due to its relatively low toxicity.

Parameter $M(0)$ indicated the start point of PAHs accumulation in the new development green spaces, namely the average PAH baseline of Beijing soils. Table 1 showed the model fitted $M(0)$ of PHE and BaP in Beijing soils were $24.7 \mathrm{ng} \mathrm{g}^{-1}$ and $17.7 \mathrm{ng} \mathrm{g}^{-1}$ respectively. According to the regression equations in Fig. 2, we could calculate the baseline concentration of the total PAHs was $267 \mathrm{ng} \mathrm{g}^{-1}$. The result was in agreement with the independent investigations of Ma et al. (2005) and Jiao et al. (2009) who reported the median concentrations of PAHs in pristine soils of Beijing as $228 \mathrm{ng} \mathrm{g}^{-1}$ and $260 \mathrm{ng} \mathrm{g}^{-1}$, respectively.

\subsection{Predictions of PAHs accumulation}

The dynamics of PHE and BaP accumulation in urban soils of Beijing might be delineated by Equation (5), in which $k_{i}, M(0)$, and $I_{0}$ were obtained from Equation (8) (Table 1). The PHE and BaP of the soils steadily increased over the duration of urban development (Fig. 5). As a scenario simulation, we assumed the boundary conditions of the model will stay stable in the next 40 years. According to antilog of the results, the average concentrations of PHE and BaP were $24.7 \mathrm{ng} \mathrm{g}^{-1}$ and $17.7 \mathrm{ng} \mathrm{g}^{-1}$ in the year of 1978 then increased gradually with time and would reach to $866 \mathrm{ng} \mathrm{g}^{-1}$ and $230.6 \mathrm{ng} \mathrm{g}^{-1}$ in 2048 respectively.

The accumulation trends of the LMW PAHs, the HMW PAHs and the total PAHs were estimated based on the predictions of PHE and BaP (Fig. 6). The total PAH concentrations in urban soils of Beijing increased from the baseline of $267 \mathrm{ng} \mathrm{g}^{-1}$ to $1854 \mathrm{ng} \mathrm{g}^{-1}$ in the past 30 years (1978-2008) and continue growing to $3631 \mathrm{ng} \mathrm{g}^{-1}$ in the following 40 years. The concentration ratio of LMW PAHs to total PAHs were $18.0 \%$ in the year of 1978 but rising to $33.1 \%$ in the year of 2048 (Fig. 6). The LMW PAHs would become the more important contributor to the increases of total PAH contents in the future.

The dynamics of PAHs accumulations over time depended on the physicochemical characteristics of PAH species and the origins of PAH emissions. Over the development period, Beijing had continuingly evolving PAH emission sources as the nature of combustions and consumption patterns of fuels changed. From 1978 to 2008, the total energy consumption in Beijing increased 3 folds (Fig. 7) and the number of motor vehicle expanded by 40 times. Meanwhile, efficiency of energy utilization increased beginning in 1990s (Fig. 7) resulting in reduced PAH emissions. The coal-fired industrial combustions that favor emissions of HMW PAHs were gradually being replaced by the more efficiency and cleaner combustion of fossil-based liquid fuels and natural gas (Gulyurtlu et al., 2003; Oanh et al., 1999). Consequently, emissions of LMW PAHs increased (Liu et al., 2001) resulting in faster accumulation of PHE over time. The shifts of PAH species was demonstrated by the relative contributions of LMW PAHs and HMW PAHs toward the total PAHs over the time of development (Fig. 6). Similar 

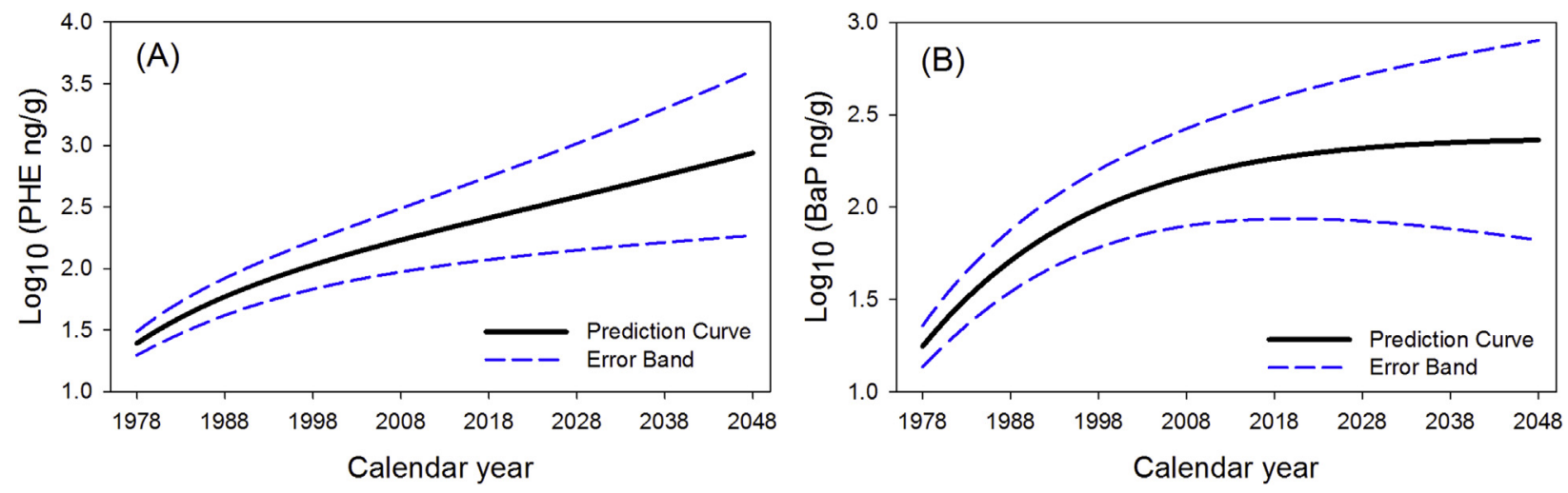

Fig. 5. Predictions of PHE and BaP accumulating in urban soils of Beijing, 1978 to 2048.

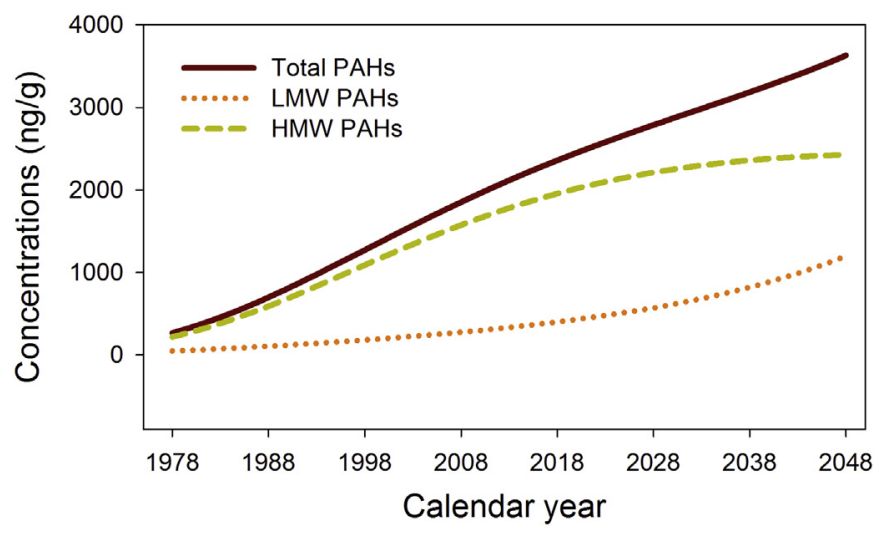

Fig. 6. Predictions of PAHs accumulating in urban soils of Beijing, 1978 to 2048.

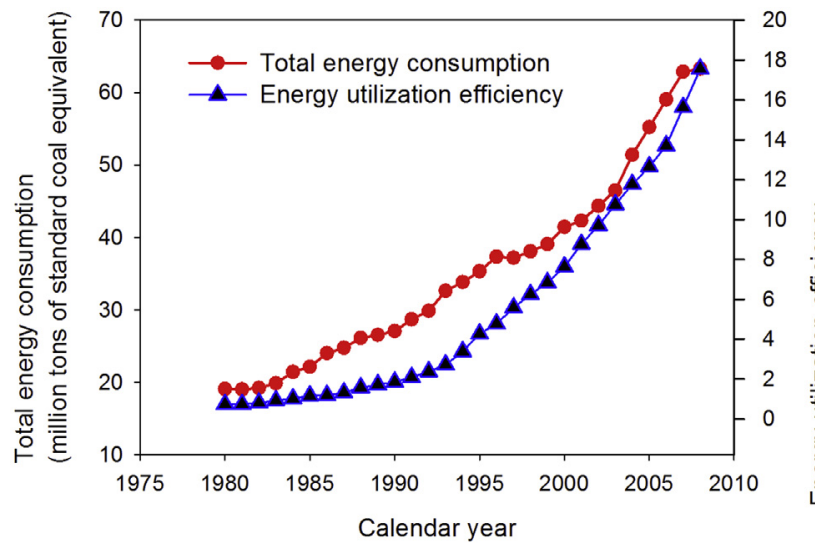

Fig. 7. Total energy consumption and energy utilization efficiency in Beijing, 1980 to 2008.

trends were documented in the United States in the 1970s as coal was being replaced by oil and natural gas in space heating (Lima et al., 2002; Liu et al., 2005) and cooking (Chuang et al., 1991; Zhu and Wang, 2003).

\section{Conclusions}

We used the regression modeling approach to simulate the historical processes of PAHs accumulation in urban soils. The key parameters of $k_{i}, M(0)$, and $I_{0}$ were estimated from the nonlinear regression analysis. The impacts of urbanization and industrial transformation on PAH emissions were revealed. The total PAH concentrations in the urban soils of Beijing were increasing with time during urbanization processes. LMW PAHs had higher accumulation rates than HMW PAHs. It suggested that the increments of PAH emissions in Beijing were shifting to LMW PAHs, such as PHE, owing to the improving energy efficiency of the city.

The regression modeling approach was an effective way to reconstruct the pollution history of urban soil and to study the connections between urbanization process and soil pollution. The model concept was simple and the data requirements of this approach could be readily satisfied. This approach was applicable in other metropolitan cities as long as we have the building age of green spaces and their soil pollutant concentrations. The low regression performance ( $R^{2}$ values) of the current study mainly due to inadequate of the dataset. The model uncertainty could be reduced by predetermining the key parameters $k_{l}$ or $k_{i}$ in target city, or obtaining more sampling data of $\mathrm{PAH}$ concentrations in residential soils.

\section{Acknowledgment}

We gratefully acknowledged financial supports provided by the National Natural Science Foundation of China (Grant No. 41401588 and 41173123).

\section{Appendix A. Supplementary data}

Supplementary data related to this article can be found at http:// dx.doi.org/10.1016/j.envpol.2014.11.025.

\section{References}

Aronson, D., Printup, H., Shuler, K., Howard, P., 1998. In: Agency, U.S.E.P. (Ed.) Chemical Fate Half-lives for Toxics Release Inventory (TRI) Chemicals.

Augusto, S., Máguas, C., Matos, J., Pereira, M.J., Soares, A., Branquinho, C., 2009. Spatial modeling of PAHs in lichens for fingerprinting of multisource atmospheric pollution. Environ. Sci. Technol. 43, 7762-7769.

BMEPB, 2003. Beijing Environmental Statement (in Chinese), 1981-2003. Beijing Municipal Environmental Protection Bureau, Beijing.

BSB Beijing Statistical Bureau, 2009. Beijing Statistical Yearbook 2009 (in Chinese), China Statistical Press, Beijing.

Chen, W., Chang, A.C., Wu, L., 2007. Assessing long-term environmental risks of trace elements in phosphate fertilizers. Ecotoxicol. Environ. Saf. 67, 48-58.

Chen, W., Lu, S., Peng, C., Jiao, W., Wang, M., 2013. Accumulation of Cd in agricultural soil under long-term reclaimed water irrigation. Environ. Pollut. 178, 294-299.

Chiou, C.T., Sheng, G., Manes, M., 2001. A partition-limited model for the plant uptake of organic contaminants from soil and water. Environ. Sci. Technol. 35 1437-1444. 
Chuang, J.C., Mack, G.A., Kuhlman, M.R., Wilson, N.K., 1991. Polycyclic aromatic hydrocarbons and their derivatives in indoor and outdoor air in an eight-home study. Atmos. Environ. Part B-Urban Atmos. 25, 369-380.

Galván, L., Olías, M., Fernandez de Villarán, R., Domingo Santos, J.M., Nieto, J.M. Sarmiento, A.M., Cánovas, C.R., 2009. Application of the SWAT model to an AMD-affected river (Meca River, SW Spain). Estimation of transported pollutant load. J. Hydrol. 377, 445-454.

Gocht, T., Ligouis, B., Hinderer, M., Grathwohl, P., 2007. Accumulation of polycyclic aromatic hydrocarbons in rural soils based on mass balances at the catchment scale. Environ. Toxicol. Chem. 26, 591-600.

Gulyurtlu, I., Karunaratne, D., Cabrita, I., 2003. The study of the effect of operating parameters on the PAH formation during the combustion of coconut shell in fluidised bed. Fuel 82, 215-223.

Guo, Z., Lin, T., Zhang, G., Yang, Z., Fang, M., 2006. High-resolution depositional records of polycyclic aromatic hydrocarbons in the central continental shelf mud of the East China sea. Environ. Sci. Technol. 40, 5304-5311.

Hao, R., Wan, H.-F., Song, Y.-T., Jiang, H., Peng, S.-L., 2007. Polycyclic aromatic hydrocarbons in agricultural soils of the southern subtropics, China. Pedosphere 17, 673-680.

Harrison, R.M., Smith, D.J.T., Luhana, L., 1996. Source apportionment of atmospheric polycyclic aromatic hydrocarbons collected from an urban location in Birmingham, UK. Environ. Sci. Technol. 30, 825-832.

He, F., Zhang, Z., Wan, Y., Lu, S., Wang, L., Bu, Q., 2009. Polycyclic aromatic hydrocarbons in soils of Beijing and Tianjin region: vertical distribution, correlation with TOC and transport mechanism. J. Environ. Sci. 21, 675-685.

Heywood, E., Wright, J., Wienburg, C.L., Black, H.I.J., Long, S.M., Osborn, D. Spurgeon, D.J., 2006. Factors influencing the national distribution of polycyclic aromatic hydrocarbons and polychlorinated biphenyls in British soils. Environ. Sci. Technol. 40, 7629-7635.

Jensen, H., Reimann, C., Finne, T.E., Ottesen, R.T., Arnoldussen, A., 2007. PAH-concentrations and compositions in the top $2 \mathrm{~cm}$ of forest soils along a $120 \mathrm{~km}$ long transect through agricultural areas, forests and the city of Oslo, Norway. Environ. Pollut. 145, 829-838.

Jiang Y.-F, Wang, X-T, Wang, F, Jia, Y, Wu, M--H, Sheng G,-Y, Fu, J-M, 2009 Levels, composition profiles and sources of polycyclic aromatic hydrocarbons in urban soil of Shanghai, China. Chemosphere 75, 1112-1118.

Jiao, W., Lu, Y., Wang, T., Li, J., Han, J., Wang, G., Hu, W., 2009. Polycyclic aromatic hydrocarbons in soils around Guanting Reservoir, Beijing, China. Chem. Ecol. 25, 39-48.

Kubošova, K.r., Komprda, J.i., Jarkovsky, J.i., Sanka, M., Hajek, O.e., Dusek, L. Holoubek, I., Klanova, J., 2009. Spatially resolved distribution models of POP concentrations in soil: a Stochastic approach using regression trees. Environ. Sci. Technol. 43, 9230-9236.

Lima, A.L.C., Eglinton, T.I., Reddy, C.M., 2002. High-resolution record of pyrogenic polycyclic aromatic hydrocarbon deposition during the 20th Century. Environ. Sci. Technol. 37, 53-61.

Liu, G.Q., Zhang, G., Li, X.D., Li, J., Peng, X.Z., Qi, S.H., 2005. Sedimentary record of polycyclic aromatic hydrocarbons in a sediment core from the Pearl River Estuary, South China. Mar. Pollut. Bull. 51, 912-921.

Liu, K.L., Han, W.J., Pan, W.P., Riley, J.T., 2001. Polycyclic aromatic hydrocarbon (PAH) emissions from a coal-fired pilot FBC system. J. Hazard. Mater. 84, 175-188.

Liu, S., Xia, X., Yang, L., Shen, M., Liu, R., 2010. Polycyclic aromatic hydrocarbons in urban soils of different land uses in Beijing, China: distribution, sources and their correlation with the city's urbanization history. J. Hazard. Mater. 177, 1085-1092.

Liu, Y., Liu, L., Lin, J.-M., Tang, N., Hayakawa, K., 2006. Distribution and characterization of polycyclic aromatic hydrocarbon compounds in airborne particulates of East Asia. China Particuol. 4, 283-292.

Ma, L., Chu, S., Cheng, H., Wang, X., Liu, X., Xu, X., 2005. Polycyclic aromatic hydrocarbons contamination in subsoil from outskirts of Beijing, People's Republic of China. Geoderma 129, 200-210.
Ma, W.-L., Sun, D.-Z., Shen, W.-G., Yang, M., Qi, H., Liu, L.-Y., Shen, J.-M., Li, Y.-F., 2011. Atmospheric concentrations, sources and gas-particle partitioning of PAHs in Beijing after the 29th Olympic Games. Environ. Pollut. 159, 1794-1801.

Mackay, D., 2001. Multimedia Environmental Models: the Fugacity Approach. CRC Press.

Nam, J.J., Thomas, G.O., Jaward, F.M., Steinnes, E., Gustafsson, O., Jones, K.C., 2008. PAHs in background soils from Western Europe: influence of atmospheric deposition and soil organic matter. Chemosphere 70, 1596-1602.

Oanh, N.T.K., Reutergardh, L.B., Dung, N.T., 1999. Emission of polycyclic aromatic hydrocarbons and particulate matter from domestic combustion of selected fuels. Environ. Sci. Technol. 33, 2703-2709.

Peng, C., Chen, W., Liao, X., Wang, M., Ouyang, Z., Jiao, W., Bai, Y., 2011. Polycyclic aromatic hydrocarbons in urban soils of Beijing: status, sources, distribution and potential risk. Environ. Pollut. 159, 802-808.

Peng, C., Ouyang, Z., Wang, M., Chen, W., Jiao, W., 2012. Vegetative cover and PAHs accumulation in soils of urban green space. Environ. Pollut. 161, 36-42.

Peng, C., Ouyang, Z., Wang, M., Chen, W., Li, X., Crittenden, J.C., 2013. Assessing the combined risks of PAHs and metals in urban soils by urbanization indicators. Environ. Pollut. 178, 426-432.

Poggio, L., Vrscaj, B., Hepperle, E., Schulin, R., Marsan, F.A., 2008. Introducing a method of human health risk evaluation for planning and soil quality management of heavy metal-polluted soils-An example from Grugliasco (Italy). Landsc. Urban Plan. 88, 64-72.

Ravindra, K., Sokhi, R., Van Grieken, R., 2008. Atmospheric polycyclic aromatic hydrocarbons: source attribution, emission factors and regulation. Atmos. Environ. 42, 2895-2921.

Staci, L., Simonich, R.A.H., 1994. Importance of vegetation in removing polycyclic aromatic hydrocarbons from the atmosphere. Nature 370.

Sun, J.-H., Wang, G.-L., Chai, Y., Zhang, G., Li, J., Feng, J., 2009. Distribution of polycyclic aromatic hydrocarbons (PAHs) in Henan Reach of the Yellow River, Middle China. Ecotoxicol. Environ. Saf. 72, 1614-1624.

Tao, S., Cao, H., Liu, W., Li, B., Cao, J., Xu, F., Wang, X., Coveney, R.M., Shen, W., Qin, B., Sun, R., 2003. Fate modeling of phenanthrene with regional variation in Tianjin, China. Environ. Sci. Technol. 37, 2453-2459.

Wang, R., Cao, H., Li, W., Wang, W., Wang, W., Zhang, L., Liu, J., Ouyang, H., Tao, S., 2011. Spatial and seasonal variations of polycyclic aromatic hydrocarbons in Haihe Plain, China. Environ. Pollut. 159, 1413-1418.

Wania, F., McLachlan, M.S., 2001. Estimating the influence of forests on the overall fate of semivolatile organic compounds using a multimedia fate model. Environ. Sci. Technol. 35, 582-590.

Wei, Y.-L., Bao, L.-J., Wu, C.-C., He, Z.-C., Zeng, E.Y., 2014. Association of soil polycyclic aromatic hydrocarbon levels and anthropogenic impacts in a rapidly urbanizing region: spatial distribution, soil-air exchange and ecological risk. Sci. Total Environ. 473-474, 676-684.

Wild, S.R., Obbard, J.P., Munn, C.I., Berrow, M.L., Jones, K.C., 1991. The long-term persistence of polynuclear aromatic hydrocarbons (PAHs) in an agricultural soil amended with metal-contaminated sewage sludges. Sci. Total Environ. 101, 235-253.

Wong, F., Harner, T., Liu, Q.-T., Diamond, M.L., 2004. Using experimental and forest soils to investigate the uptake of polycyclic aromatic hydrocarbons (PAHs) along an urban-rural gradient. Environ. Pollut. 129, 387-398.

Yan, W., Chi, J.S., Wang, Z.Y., Huang, W.X., Zhang, G., 2009. Spatial and temporal distribution of polycyclic aromatic hydrocarbons (PAHs) in sediments from Daya Bay, South China. Environ. Pollut. 157, 1823-1830.

Yu, X.Z., Gao, Y., Wu, S.C. Zhang, H.B., Cheung, K.C., Wong, M.H., 2006. Distribution of polycyclic aromatic hydrocarbons in soils at Guiyu area of China, affected by recycling of electronic waste using primitive technologies. Chemosphere 65, 1500-1509.

Zhu, L., Wang, J., 2003. Sources and patterns of polycyclic aromatic hydrocarbons pollution in kitchen air, China. Chemosphere 50, 611-618. 